\title{
GENÉTICA DE LA RESISTENCIA A ROYA AMARILLA CAUSADA POR Puccinia striiformis f. sp. tritici W. EN TRES GENOTIPOS DE TRIGO (Triticum aestivum L.)
}

\section{GENETICS OF THE RESISTANCE TO YELLOW RUST CAUSED BY Puccinia striiformis f. sp. tritici W. IN THREE GENOTYPES OF WHEAT (Triticum aestivum L.)}

\author{
María F. Rodríguez-García ${ }^{1,2}$, Reyna I. Rojas-Martínez', Julio Huerta-Espino²*, Héctor E. \\ Villaseñor-Mir ${ }^{2}$, Emma Zavaleta-Mejía ${ }^{1}$, José S. Sandoval-Islas ${ }^{1}$ y José F. Crossa-Hiriart ${ }^{3}$
}

\begin{abstract}
'Colegio de Postgraduados, Campus Montecillo, Postgrado en Fitosanidad, Montecillo, Texcoco, Edo. de México. ${ }^{2}$ Instituto Nacional de Investigaciones Forestales, Agrícolas y Pecuarias, Campo Experimental Valle de México, Coatlinchán, Texcoco, Edo. de México. ${ }^{3}$ Centro Internacional de Mejoramiento de Maíz y Trigo, El Batán, Texcoco Edo. de México.
\end{abstract}

*Autor para correspondencia (j.huerta@cgiar.org)

\section{RESUMEN}

La roya amarilla del trigo causada por Puccinia striiformis f. sp. tritici se ha convertido en una enfermedad de importancia a nivel mundial en los últimos años. La resistencia genética en variedades es la estrategia más efectiva para el control de esta enfermedad. En la actualidad existen genotipos de trigo que han mostrado resistencia en diferentes años y ambientes de producción. El objetivo del presente estudio fue determinar el tipo de resistencia y estimar el número de genes que condicionan la resistencia a roya amarilla en los genotipos Glenlea, Romero 73 y Bonza 63. Se utilizó como progenitor susceptible a Avocet- $Y r A$, se generaron tres poblaciones, las cuales se avanzaron hasta obtener familias $\mathrm{F}_{5}$. Las poblaciones se evaluaron en un ensayo con un diseño experimental de bloques completos al azar, bajo epidemias artificiales del hongo causante de la roya amarilla, en la estación experimental del INIFAP-CEVAMEX en Chapingo, México, durante el ciclo primavera-verano $(\mathrm{P}-\mathrm{V})$ 2015. La formación de rocío al $100 \%$ y temperaturas entre 10 y $20^{\circ} \mathrm{C}$ fueron favorables para el desarrollo de la enfermedad, lo que permitió determinar que la resistencia de Bonza 63, Glenlea y Romero 73 se debe al efecto de genes menores de tipo cuantitativo. El comportamiento de las familias y el análisis de $X^{2}$ indicó la presencia de tres genes que confieren resistencia de planta adulta (RPA) a roya amarilla en los genotipos Bonza 63 y Romero 73. Se determinó que la variedad Glenlea posee de cuatro a cinco genes de RPA. Bonza 63, Glenlea y Romero 73 poseen altos niveles de resistencia en planta adulta a las diversas razas presentes en las principales regiones trigueras de México y son adecuados para usarse como progenitores en los programas de mejoramiento para lograr una resistencia durable a roya amarilla.

Palabras clave: Genes, planta adulta, razas, durable.

\section{SUMMARY}

The wheat yellow rust caused by Puccina striiformis $\mathrm{f}$. sp. tritici has become a disease of global importance in the last few years. The genetic resistance in varieties is the strategy that has best supported the control of this disease. Currently several genotypes exist that have shown resistance in different years and environments. The objective of this study was to determine the type of resistance and to estimate the number of genes that condition the resistance to yellow rust in the Glenlea, Romero 73 and Bonza 63 genotypes. The susceptible progenitor used was Avocet-YrA, three populations were developed and advanced until $F_{5}$ families were obtained. The populations were evaluated under artificial yellow rust epidemics using a complete randomized blocks experimental design at the experimental station of the INIFAPCEVAMEX in Chapingo, Mexico, during the Spring-Summer 2015 cycle. Dew formation at $100 \%$ and temperatures between 10 and $20{ }^{\circ} \mathrm{C}$ were favorable for the development of the disease which allowed to determine that the resistance of Bonza 63, Glenlea and Romero 73 genotypes is due to the effects of minor genes of quantitative effects. The performance of families and the analysis of $X^{2}$ indicated the presence of three genes that confer adult plant resistance (APR) to yellow rust in the Romero 73 and Bonza 63 genotypes. It was determined that the Glenlea variety possesses from four to five APR genes. Bonza 63, Glenlea and Romero 73 possess high levels of adult plant resistance to the various races present in the main wheat regions of Mexico and are suitable to be used as progenitors in wheat improvement programs to achieve durable resistance to yellow rust.

Index words: Genes, adult plant, races, durable.

\section{INTRODUCCIÓN}

A nivel mundial el trigo harinero (Triticum aestivum L.) es el cultivo que ocupa la mayor área sembrada (FAOSTAT, 2018). Su producción es afectada por factores bióticos y abióticos (Beddow et al., 2015). Entre los factores bióticos, las enfermedades como las royas son ocasionadas por diferentes especies del género Puccinia. Fetch et al. (2011) mencionan que las royas son las más devastadoras, ya que históricamente han causado pérdidas considerables en rendimiento de este cereal en todo el mundo. La roya amarilla (RA), causada por P. striiformis f. sp. tritici, es una enfermedad que ocurre en la mayoría de las áreas con climas húmedos y fríos, está considerada como la principal limitante que afecta la producción de trigo en estas áreas (Chen et al., 2014; Wellings, 2011). Hovmøller et al. (2011) mencionan que las epidemias de mayor impacto desde el año 2000 se han presentado en zonas más cálidas, con temperaturas de 12 a $28{ }^{\circ} \mathrm{C}$, donde la enfermedad se consideraba sin importancia o ausente, la base de este cambio parece ser la tolerancia del patógeno a temperaturas más elevadas (mayores de $25^{\circ} \mathrm{C}$ ) y la capacidad para esporular en un periodo de tiempo más corto.

Beddow et al. (2015) estimaron que se pierden 5.47 
millones de toneladas de trigo cada año por roya amarilla, lo que equivale a una pérdida económica de US\$ 979 millones por año. Solh et al. (2012) indican que se han producido con frecuencia epidemias de roya amarilla en varios países que han causado pérdidas del 1 al $25 \%$; sin embargo, en 2010 se registraron pérdidas de hasta 80 \% en el Oriente Medio y el Norte de África. En México durante los ciclos de cultivo de 2014, se produjo una epidemia donde se identificaron las razas fisiológicas MEX14.141 con la fórmula de avirulencia/virulencia: Yr7, 5, 10, 15, 24, 26, YrSp y YrPoll/Yr2, 3, 6, 7, 8, 9, 17, 27 y 31; y MEX14.146 (Yr5, 10, 15, 24, 26, YrSp y YrPoll/Yr7, 2, 3, 6, 7, 8, 9, 17, 27 y 37); la única diferencia entre estas dos razas es la virulencia para el gen Yr1 en MEX.14.146 (Zhang et al., 2019); estas nuevas combinaciones de virulencia Yr27 y Yr37 provocaron pérdida de resistencia en la variedad Nana F2007, recomendada para siembras de temporal en México y Luminaria F2012 (Solís et al., 2016), recomendada para siembras en áreas de riego en El Bajío.

Los genes que confieren resistencia a royas en trigo se clasifican en tres categorías: 1) los que confieren resistencia en todas las etapas de crecimiento, ésta se manifiesta desde plántula y se mantiene durante todo el ciclo de crecimiento en ausencia de virulencia; 2) los genes que sólo confieren resistencia en planta adulta (RPA), cuya resistencia se hace más efectiva en la hoja bandera, que son de raza-específica, y 3) los genes que confieren resistencia parcial, a menudo como resistencia de campo y son parciales; es decir, se expresan fenotipos con diferentes niveles de infección a la enfermedad; este tipo de resistencia es conocida como resistencia de raza no específica (Lagudah, 2011). Existen otros genes que confieren resistencia de raza no específica, como Yr36 y Yr39, que son más efectivos a temperaturas altas (mayores de $25^{\circ} \mathrm{C}$ ) y se designan como genes de resistencia de planta adulta a temperatura alta (HTAP), pero su efectividad es dudosa a temperaturas por debajo de los $18{ }^{\circ} \mathrm{C}$ (Uauy et al., 2005). Se requieren varios genes que condicionen la resistencia parcial (pirámide de genes), que sean de efecto aditivo para conferir niveles altos o adecuados de resistencia (Singh et al., 2000; 2005). Actualmente, el uso de genes de raza específica y la alta variación genética en las poblaciones del patógeno, aunados a la rápida tasa de selección de nuevas razas virulentas, ha forzado a los mejoradores de trigo a concentrarse en estrategias que combinan varios genes de resistencia específica y de raza no-específica para aumentar la durabilidad de la resistencia (Maccaferri et al., 2015). En el caso de la roya amarilla se deben combinar de 4 a 5 genes de efecto aditivo o de raza no específica para reducir el progreso de la enfermedad a niveles bajos, donde sólo se puedan observar porcentajes mínimos de severidad (de 5 a 10 \% de infección en hoja bandera) (Singh et al., 2000; 2011).

Recientemente se ha observado que los trigos denominados como antiguos (Huasteco M81, Orizaba 77 y Chapingo 48) poseen buenos niveles de resistencia a royas; en los últimos años autores como Bulli et al. (2016) han identificado 127 QTL que proporcionan resistencia a roya amarilla al realizar un análisis de asociación del genoma completo en accesiones de trigo provenientes de 67 países, dicho estudio proporciona una visión general de la gran diversidad de fuentes de resistencia a roya amarilla existentes en las colecciones de trigo en todo el mundo. Por otra parte, Suaste et al. (2015) estudiaron la variabilidad genética existente en colecciones de trigo con la finalidad de detectar fuentes donadoras de genes que permitan incrementar la expresión de los caracteres de interés agronómico y fitopatológico.

En la actualidad, las variedades de trigo harinero Bonza 63, Glenlea y Romero 73 han mantenido, desde su liberación, niveles de resistencia aceptables a las diversas razas de roya amarilla que se han presentado en México y en otras partes del mundo; en este contexto, el objetivo del presente trabajo fue determinar el tipo de resistencia a roya amarilla que poseen las tres variedades mencionadas y estimar el número de genes que condicionan la resistencia de estos genotipos.

\section{MATERIALES Y MÉTODOS}

\section{Material genético}

Se utilizaron los genotipos de trigo Bonza 63, Glenlea y Romero 73, los cuales presentan diferentes niveles de resistencia a roya amarilla y el genotipo susceptible Avocet-YrA, los cuales se describen a continuación:

Avocet-YrA es una línea proveniente de una re-selección de la variedad australiana Avocet que carece de genes de resistencia a roya amarilla y es susceptible en plántula y planta adulta (100S) a todas las razas fisiológicas de roya amarilla (RA) que existen en México (Huerta et al., 2012), su genealogía y pedigrí es: WW119/WW151//EGRET (YrA-30Y).

Bonza 63 es una variedad de trigo harinero sin aristas, liberada en el año 1963 por el Instituto Colombiano Agropecuario (ICA), su genealogía es: RIO NEGRO/2*BONZA 55; su ciclo vegetativo es de $145 \mathrm{~d}$, con una altura de planta de $100 \mathrm{~cm}$, posee buena calidad industrial y recomendable en Colombia 
para ambientes de producción ubicados en alturas de 2400 a 2700 msnm (Zapata y López, 1967, Com. Pers.)', ha mantenido niveles altos (20MR-MS) de resistencia a roya amarilla desde su liberación.

Glenlea es un trigo harinero rojo de primavera, sin aristas, fue formado por el Plant Science Department, University of Manitoba, Winnipeg, Canadá. Fue el primer trigo harinero de primavera utilizado con licencia en ese país, fue liberado en 1972 y se derivó de la cruza (Pembina ${ }^{2} \times$ Bage $\times$ × CB100 (Evans et al., 1972). Su ciclo vegetativo en ambientes de temporal en México es de 135 d, con una altura de 105 $\mathrm{cm}$. Glenlea ha mantenido niveles altos (de 5 a $20 \%$ de infección en hoja bandera) de resistencia a roya amarilla desde su liberación.

Romero 73 es una variedad de trigo harinero sin aristas, liberada en 1973 por el Instituto Nacional de Investigaciones Agropecuarias, Estación Experimental Santa Catalina, Ecuador; se derivó de la cruza FrocorKenya 58/Newthatch $\times$ Bonza $^{3}$; su ciclo vegetativo es de $150 \mathrm{~d}$, con una altura de planta de $100 \mathrm{~cm}$; en cuanto a reacción a enfermedades, Romero 73 fue descrita como moderadamente resistente a roya amarilla (10MR) y a roya del tallo (10MR) y moderadamente susceptible a roya de la hoja (20MS) (Lalama, 1974). Hasta el ciclo primaveraverano 2017 Romero 73 ha mantenido sus niveles de resistencia a roya amarilla de 10 a $20 \mathrm{MS}$.

\section{Obtención de familias $F_{5}$}

Las poblaciones biparentales se obtuvieron siguiendo un dialélico parcial para obtener las diferentes cruzas (Avocet-YrA × Bonza 63, Avocet-YrA $\times$ Glenlea y AvocetYrA $\times$ Romero 73) mediante el método emasculaciónpolinización manual descrito por Mellado (2007); la generación de las líneas endogámicas recombinantes $F_{5}$ se realizó siguiendo la metodología descrita por Huerta et al. (2012) y Basnet et al. (2013). Durante el ciclo otoñoinvierno (O-I) 2012-2013, en los invernaderos del Campo Experimental Valle de México (CEVAMEX) del Instituto Nacional de Investigaciones Forestales Agrícolas y Pecuarias (INIFAP), ubicado en Chapingo, Texcoco, Edo. de México a $19^{\circ} 53^{\prime}$ latitud $N$ y $99^{\circ} 53^{\prime}$ longitud $\mathrm{O}$ a una altitud de 2250 m. En el ciclo P-V 2013 en INIFAP-CEVAMEX se sembró la $F_{1}$ de cada cruzamiento de forma mateada en parcelas contiguas y de cada $F_{1}$ se cosecharon cinco plantas al azar; de estas cinco plantas se usó la semilla de tres para avanzar a la siguiente generación y las otras dos se mantuvieron como reserva. En el ciclo 0-I 2013-2014 se sembró la generación $F_{2}$ en dos surcos dobles de $11 \mathrm{~m}$

\footnotetext{
'Zapata B. M. y L. López (1967) El cultivo del trigo. Desplegable de Divulgación No. 5. Instituto Colombiano Agropecuario. Bogotá, Colombia.
}

de largo en parcelas contiguas, en un lote experimental del Campo Experimental Bajío del INIFAP, ubicado en Celaya, Guanajuato a $20^{\circ} 34^{\prime}$ latitud N y $100^{\circ} 49^{\prime}$ longitud O, a 1768 msnm. De la progenie de cada una de las tres plantas se cosecharon 50 plantas $F_{2}$ al azar que dieron origen a 150 familias $F_{3}$ por cada cruza, de las cuales se sembraron 118 familias de las cruzas Avocet-YrA/Bonza 63 y Avocet-YrA/ Romero 73; y 144 familias de la cruza Avocet-YrA/Glenlea. La generación $\mathrm{F}_{4}$ se avanzó durante el ciclo 0-I 2014-2015 para dar origen a la generación $\mathrm{F}_{5}$, sobre la cual se realizó el presente estudio.

\section{Evaluación de las familias en plántula}

En el Laboratorio Nacional de Royas y Otras Enfermedades del Trigo (LANARET) del INIFAP-CEVAMEX, bajo condiciones de invernadero ( $T$ máx. $24{ }^{\circ} \mathrm{C}$, $\mathrm{T}$ mín. $7^{\circ} \mathrm{C}$ ) se evaluó la resistencia de las familias $F_{5}$ de las poblaciones Avocet-YrA/Bonza 63, Avocet-YrA/Romero 73 y Avocet-YrA/Glenlea durante los meses de octubre y noviembre de 2015, para lo cual se sembraron las familias en charolas de plástico de $20 \times 30 \times 6 \mathrm{~cm}$ a las que se les agregó una mezcla de tierra estéril y peat moss en una proporción 60:40, se marcaron pequeños orificios y se colocaron de 8 a 9 semillas por familia y 30 familias por charola; posteriormente, a los 11 d después de la siembra, las plántulas se inocularon con una suspensión de urediniosporas de las razas de roya amarilla MEX96.11, MEX08.13 y CMEX14.25 a una concentración de $1 \times$ $10^{6}$ urediniosporas $\mathrm{mL}^{-1}$. Las urediniosporas fueron suspendidas en aceite mineral (Soltrol ${ }^{\circledR}$ 170; Chevron Phillips Chemical Company, The Woodlands, Texas, Estados Unidos) y asperjadas con un atomizador conectado a un compresor. Las plántulas inoculadas se colocaron en una cámara bioclimática con temperaturas de $4{ }^{\circ} \mathrm{C}$ por $24 \mathrm{~h}$ y rocío al $100 \%$ por $1 \mathrm{~h}$. Posteriormente, se trasladaron al invernadero y después de 15 d de inoculación se registró su reacción a la roya amarilla mediante la escala propuesta por Roelfs et al. (1992), donde lecturas del 1 al 6 se consideran resistentes y del 7 al 9 susceptibles. Las familias y los progenitores correspondientes a cada cruza se sembraron en bloques completos al azar, cada bloque fue constituido por 30 líneas distribuidas en cinco hileras y seis columnas con dos repeticiones.

\section{Evaluación de las familias en planta adulta}

Las familias $F_{5}$, los progenitores resistentes (Bonza 63, Glenlea, Romero 73) y el susceptible (Avocet-YrA) se evaluaron por su resistencia en planta adulta en un ensayo en campo mediante un diseño experimental de bloques completos al azar con una sola repetición, en la estación experimental del INIFAP-CEVAMEX durante el verano de 2015. Cada parcela incluyó aproximadamente 70 plantas 
dispuestas en dos filas paralelas de $1 \mathrm{~m}$. A un lado de cada parcela los bloques fueron constituidos por 30 familias y alrededor del lote experimental se sembró una mezcla de genotipos susceptibles a roya amarilla (Moroco, Avocet +Yr37 y seis líneas que poseen los genes Yr3, Yr9 y Yr27 derivadas de la cruza Avocet/Attila) que actuaron como fuente de inóculo.

Para hacer una eficiente evaluación y clasificación de las familias $F_{5}$ por su reacción a roya amarilla fue necesario crear epidemias artificiales mediante tres inoculaciones, en las que se utilizó una suspensión de urediniosporas de los aislamientos MEX96.11 con su fórmula de avirulencia/ virulencia Yr7, 4, 5, 8, 10, 15, 17, 24, Sp/2, 3, 6, 7, 9, 27, A (William et al., 2003) y MEX08.13 que es avirulenta a Yr27 y virulenta a Yr37. Las urediniosporas fueron suspendidas en aceite mineral (Soltrol@ 170; Chevron Phillips Chemical Company, The Woodlands, Texas, Estados Unidos) y asperjadas con un atomizador manual. Durante el ciclo del cultivo se identificó un aislamiento (CMEX14.25) que combina virulencia para Yr27 y Yr37 que estuvo presente en el experimento.

La severidad de la enfermedad se registró cuando el progenitor susceptible (Avocet-YrA) alcanzó niveles de 80 a $100 \%$; se utilizó la escala de Cobb modificada (Peterson et al., 1948) y la respuesta del hospedante a la infección se determinó de acuerdo con Roelfs et al. (1992), donde R: resistente, uredinios diminutos; MR: moderada resistencia, uredinios pequeños; MS: moderada susceptibilidad, uredinios pequeños de tamaño moderado y S: susceptible, uredinios grandes. Por otra parte, en los progenitores resistentes y susceptibles se registró la presencia 0 ausencia del marcador morfológico denominado necrosis en la punta de la hoja ( $L t n$ : leaf tip necrosis).

\section{Clasificación de familias}

Con base en la severidad de la enfermedad y en la respuesta a la infección, las familias $F_{5}$ fueron clasificadas en tres categorías fenotípicas de acuerdo con Singh y Rajaram (1992), líneas homocigotas parentales tipo resistente (LHPTR), líneas homocigotas parentales tipo susceptible (LHPTS) y líneas con respuesta diferente a los dos padres (OTROS).

\section{Análisis genético}

Los experimentos de campo se llevaron a cabo con una serie sencilla; la estimación del número de genes se realizó mediante el análisis de segregación mendeliana tradicional y las frecuencias fenotípicas observadas se compararon con las frecuencias fenotípicas esperadas mediante la prueba de chi-cuadrada $\left(\chi^{2}\right)$ (Singh y Rajaram,
1992), técnica utilizada en otros trabajos de investigación de la misma naturaleza como en los de Huerta et al. (2012) y Ponce-Molina et al. (2018).

\section{RESULTADOS Y DISCUSIÓN}

\section{Evaluación fenotípica de la resistencia a roya amarilla en etapa de plántula}

En las poblaciones Avocet-YrA/Bonza 63, Avocet-YrA/ Romero 73 y Avocet-YrA/Glenlea no se encontraron diferencias entre el progenitor susceptible y los resistentes, ambos tuvieron una reacción de susceptibilidad, lo que indica que los genotipos Bonza 63, Romero 73 y Glenlea no poseen genes de resistencia de raza específica a roya amarilla para las razas MEX96.11, MEX08.13 y CMEX14.25; el tipo de resistencia que poseen es de planta adulta, de patogenia lenta u horizontal. Dicha resistencia se caracteriza por expresar susceptibilidad en etapa de plántula y resistencia en planta adulta, como lo indican Lagudah (2011) y Niks et al. (2011), comportamiento similar observado en campo e invernadero en cuanto a resistencia a roya amarilla en Bonza 63, Romero 73 y Glenlea. Por otra parte, Singh et al. (2015) indican que genotipos con resistencia de planta adulta son ideales para tomarlos como fuente de resistencia a royas; es decir, Bonza 63, Romero 73 y Glenlea son genotipos idóneos para incorporarlos en los programas de mejoramiento de trigo con enfoque hacia resistencia a roya amarilla en México.

\section{Evaluación fenotípica de la resistencia a roya amarilla en etapa de planta adulta}

La formación de rocío y temperaturas entre 10 y $20^{\circ} \mathrm{C}$ durante el periodo de infección fueron favorables para el desarrollo de la roya amarilla en la estación experimental INIFAP-CEVAMEX durante el ciclo P-V 2015, lo que permitió realizar la evaluación y clasificación de las familias Avocet-YrA/Bonza 63, Avocet-YrA/Glenlea y Avocet-YrA/ Romero 73. El progenitor susceptible Avocet-YrA presentó $100 \%$ de severidad de la enfermedad (SFE) y reacción de susceptibilidad (S), mientras que los progenitores resistentes presentaron $10 \%$ de severidad y reacción de moderada susceptibilidad (MS) para Bonza 63 y Romero 73, mientras que Glenlea presentó $5 \%$ de severidad y una reacción de moderada resistencia (MR).

Al analizar el comportamiento de las familias en relación con los niveles de infección, no se observó una distribución discreta de clases que pudiese indicar la presencia de genes de resistencia de raza específica o de efectos mayores, lo que se observó fue una variación continua o distribución aproximadamente normal, lo que indica que la resistencia que poseen los genotipos Bonza 63, 
Glenlea y Romero 73 se debe al efecto de genes menores y es de tipo cuantitativo, como se observa en la Figura 1. Estos resultados coinciden con lo reportado por Singh et al. (2011), en términos de distribución fenotípica en poblaciones con resistencia lenta a la enfermedad como Pavón 76 y Parula.

\section{Estimación del número de genes que condicionan resistencia a roya amarilla en familias $F_{5}$}

La evaluación realizada en el ciclo P-V 2015 de las familias de las cruzas Avocet-YrA/Bonza 63, Avocet-YrA/Romero 73 y Avocet-YrA/Glenlea, con base en el porcentaje de severidad final, permitió su clasificación en tres categorías fenotípicas. En el Cuadro 1 se presentan los resultados de las proporciones fenotípicas de dichas poblaciones; con base en el número de líneas homocigotas parentales tipo resistentes (LHPTR), y susceptibles (LHPTS) se observa que en las poblaciones Avocet-YrA/Romero 73 y AvocetYrA/Bonza 63 la resistencia está conferida por tres genes de efecto aditivo. En la población Avocet-YrA/Glenlea el análisis de $X^{2}$ mostró que las frecuencias observadas se ajustaron a las esperadas para cuatro o cinco genes, lo que indica que la resistencia a roya amarilla en Glenlea está conferida por cuatro y hasta cinco genes de efecto aditivo.

Singh et al. (2005) indicaron que la resistencia de patogenia lenta (slow rusting) es la más utilizada en los programas de mejoramiento genético para el control de las royas, y que la búsqueda de genes de resistencia para su control debe ser un trabajo constante, debido a que ciclo tras ciclo de producción de trigo aparecen nuevas razas fisiológicas que sobrepasan la resistencia que poseen las variedades de reciente liberación; por lo anterior, una de las actividades preponderantes dentro de los programas de mejoramiento genético de este cereal es la búsqueda de fuentes de resistencia a estas enfermedades en variedades ya liberadas; en este tenor, Basnet et al. (2013) determinaron que la variedad Quaiu 3 posee dos tipos de resistencia (cualitativa y cuantitativa) y que este tipo de resistencia es muy eficaz para el control de la roya amarilla.
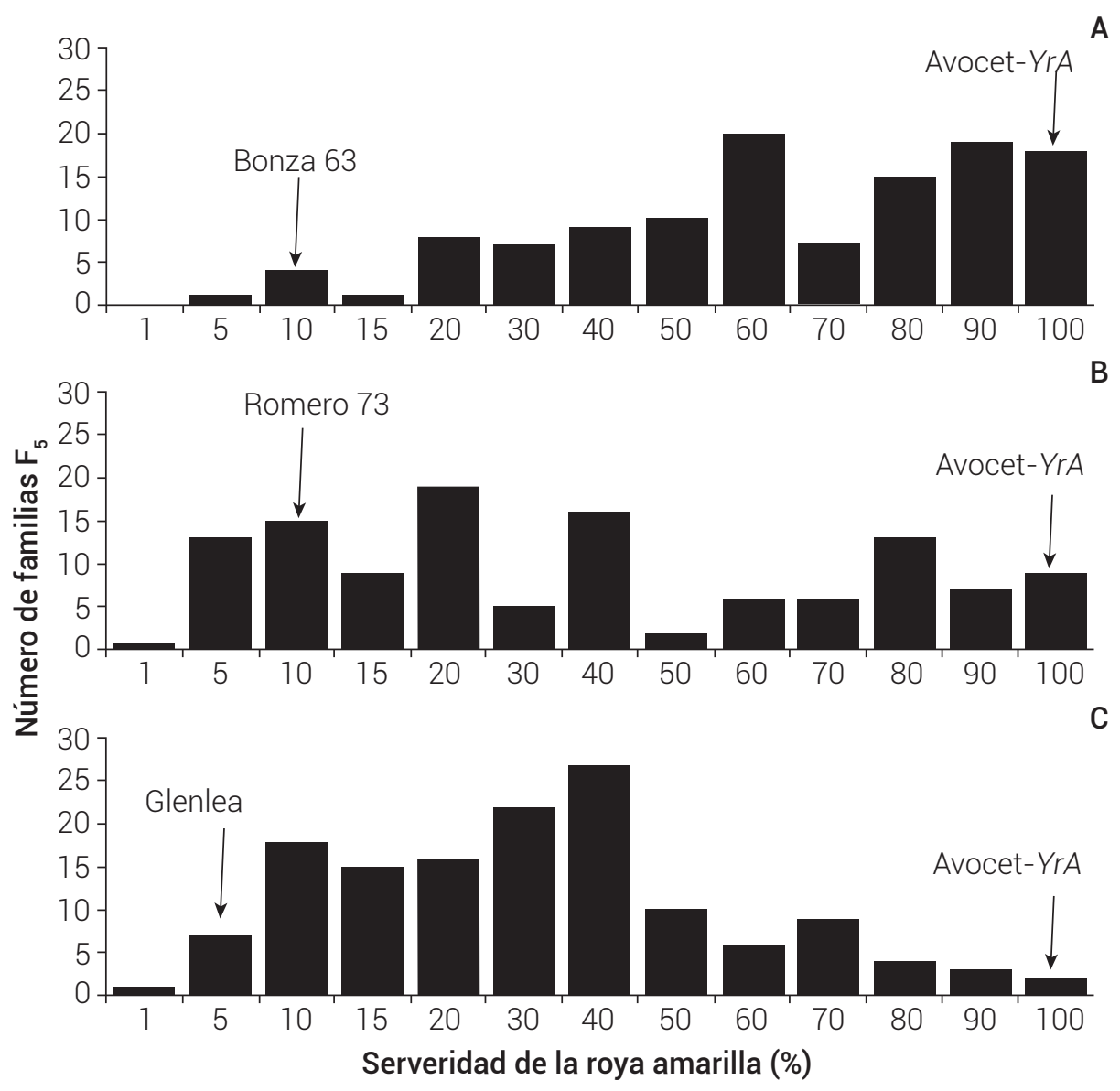

Figura 1. Distribución continua de familias $\mathrm{F}_{5}$ basada en el porcentaje de severidad final de RA de los progenitores $y$ familias: A) Avocet-YrA/Bonza 63, B) Avocet-YrA/Romero 73 y C) Avocet-YrA/Glenlea evaluadas en campo en Chapingo, México durante el ciclo P-V 2015. 
Villaseñor-Espín et al. (2009) estimaron el número de genes de resistencia a roya amarilla en variedades para la siembra de trigo de temporal y encontraron que de tres a cuatro genes de efecto aditivo condicionan la resistencia en Juchi F2000, Náhuatl F2000 y Tlaxcala F2000; por otra parte, Huerta et al. (2012) determinaron que la resistencia a roya amarilla en las variedades recomendadas para siembra de riego Cortázar S94, Bárcenas S2002 y Maya S2007 está condicionada por dos o tres genes de efecto aditivo, mientras que en Urbina S2007 está condicionada por tres o cuatro genes de la misma naturaleza.

De los tres genotipos evaluados, Glenlea es el que posee mayor número de genes de resistencia de raza no específica a roya amarilla, y con base en su baja severidad (5\%) y reacción de moderada resistencia (MR), dicho genotipo es idóneo para utilizarlo como fuente de resistencia en México y el mundo para generar nuevas líneas y conjuntar la resistencia de raza no específica y raza específica, que en los últimos años es uno de los objetivos de los programas de mejoramiento a nivel mundial para disminuir las pérdidas económicas causadas por la roya amarilla en el cultivo de trigo.

En las familias $F_{5}$ de las tres poblaciones estudiadas se observó segregación transgresiva en los dos ciclos evaluados (Figura 1); es decir, hubo familias que fueron más resistentes que los progenitores resistentes (Figura 1); esto indica que Avocet-YrA tiene un gen con efecto pequeño para roya amarilla y coincide con lo reportado por Rosewarne et al. (2013), quienes indicaron que en Avocet se han identificado siete loci de caracteres cuantitativos en investigaciones con enfoque hacia fuentes de resistencia a roya amarilla.

En el presente estudio Glenlea mostró mayor resistencia en planta adulta a roya amarilla (5MR), seguida por Romero 73 y Bonza 63, que presentaron $10 \%$ de severidad, tal resistencia es debida a que Glenlea tiene mayor número de genes de efecto aditivo (Cuadro 1); este comportamiento coincide con lo indicado por Singh y Rajaram (1993), quienes mencionan que las variedades que sólo llevan un gen de resistencia muestran niveles moderados de resistencia; sin embargo, conforme aumenta el número de genes, los niveles de resistencia también aumentan, como se demuestra en este estudio (Cuadro 1).

En las tres variedades estudiadas se observó el marcador morfológico necrosis en la punta de la hoja; dicho marcador está asociado con la presencia de los genes de resistencia en planta adulta, de patogenia lenta y de efecto pleiotrópico, denominados Lr34/Yr78/Sr57/Pm38/Ltn7 (Singh, 1992a) Lr46/Yr29/Sr58/Pm39/Ltn2 (Rosewarne et al., 2006) y Lr67/Yr46/Sr55/Pm39/Ltn3 (Herrera-Foessel et al., 2014). Dyck et al. (1985) y Lagudah et al. (2006) indicaron que Glenlea posee el gen de resistencia a roya de la hoja Lr34; dicho gen está ligado con el Yr18 (Singh, 1992b) y fue uno de los primeros trigos harineros canadienses en poseer el gen Lr34 (Kolmer y Liu, 2002); en Canadá este gen sigue siendo efectivo para roya de la hoja en dicho cultivar (Fetch et al., 2011) y en cuanto a roya amarilla, Glenlea ha mantenido los niveles de resistencia desde su liberación en 1972; dicha resistencia podría deberse a la presencia del gen Yr18.

McCallum et al. (2007) demostraron que dicho genotipo manifestó altos niveles de resistencia a roya amarilla, que fueron desde 0 hasta $36 \%$ de severidad en diversos ambientes en Canadá, EE. UU. y Nueva Zelanda; por otra parte, McCallum et al. (2016) indicaron que la eficacia y durabilidad de Lr34/Yr18 hicieron que haya sido y siga siendo la base genética de muchos genotipos de trigo en Canadá. Dyck et al. (1985) reconocieron que Lr34 condicionaba resistencia a roya de la hoja y roya del tallo en el cultivar Glenlea; éste fue el primer reporte de la naturaleza pleiotrópica de Lr34 (McCallum et al., 2016).

García-Leónetal. (2018) indicaronqueBonza63y Romero

Cuadro 1. Número de familias $F_{5}$ clasificadas en tres grupos de las cruzas entre el progenitor susceptible Avocet-YrA y los progenitores resistentes Bonza 63, Romero 73 y Glenlea frente a la mezcla de las razas MEX96.11, MEX08.13 y CMEX14.25 durante el ciclo P-V 2015.

\begin{tabular}{|c|c|c|c|c|c|c|c|}
\hline \multirow{2}{*}{ Cruza } & \multicolumn{4}{|c|}{ Número de familias $\mathrm{F}_{5}$} & \multirow{2}{*}{ No. de genes } & \multirow{2}{*}{$\chi^{2}$ Calculada } & \multirow{2}{*}{ Probabilidad } \\
\hline & LHPTR & LHPTS & OTROS & Total & & & \\
\hline Avocet-YrA/Bonza 63 & 4 & 18 & 95 & 117 & 3 & 7.7 & 0.05 \\
\hline Avocet-YrA/Romero 73 & 14 & 9 & 95 & 118 & 3 & 1.6 & 0.40 \\
\hline \multirow[t]{2}{*}{ Avocet-YrA/Glenlea } & 7 & 2 & 130 & 139 & 4 & 1.9 & 0.40 \\
\hline & & & & & 5 & 7.5 & 0.05 \\
\hline
\end{tabular}

$4 \mathrm{gl}, \mathrm{a}=0.05, \chi^{2} \mathrm{t}=9.488$; LHPTR: líneas homocigotas parentales tipo resistente; LHPTS: líneas homocigotas parentales tipo susceptible; OTROS: líneas con respuesta diferente a los dos padres. 
73 poseen los genes de resistencia en planta adulta a roya del tallo denominados Sr58 y Sr57, respectivamente; Sr57 se encuentra ligado a los genes Lr34 (Dyck, 1987), Yr18 (Singh, 1992a) y Sr57 (Mclntosh et al., 2012). Por su parte, el gen Sr58 se encuentra ligado a los genes Lr46 (Singh et al., 1998), Yr29 (William et al., 2003) y Sr58 (Mclntosh et al., 2014); dichos genes de resistencia aún siguen siendo efectivos en muchas partes del mundo (Singh et al., 2015). Se ha identificado que los genes Yr18 y Yr29 tienen un efecto similar en la resistencia a roya amarilla y de la hoja (Lr34 y Lr46) (Singh et al., 2011). La presencia de alguno de estos genes en Bonza 63 y Romero 73 explica el nivel alto de resistencia a roya amarilla que se observó en las variedades y dicha resistencia sigue siendo efectiva.

\section{CONCLUSIONES}

Las variedades Bonza 63, Romero 73 y Glenlea no poseen genes de resistencia de plántula a los aislamientos de roya amarilla MEX96.11, MEX08.13 y CMEX14.25. Glenlea y Romero 73 poseen cuatro y tres genes de resistencia de efecto aditivo, respectivamente y el gen Yr18 es común en ambos genotipos. Bonza 63 posee el gen Yr29 y dos genes más de efecto aditivo. Los tres genotipos poseen genes de resistencia de raza no específica y son fuentes de resistencia valiosa para incorporarse en las nuevas líneas generadas por los programas de mejoramiento genético de trigo.

\section{AGRADECIMIENTOS}

Al Consejo Nacional de Ciencia y Tecnología (CONACYT) por la beca otorgada para la realización de la presente investigación y al fondo sectorial SAGARPA-CONACYT (Proyecto No.146788).

\section{BIBLIOGRAFÍA}

Basnet B. R., R. P. Singh, S. A. Herrera-Foessel, A. M. H. Ibrahim, J. HuertaEspino, V. Calvo-Salazar and J. Rudd (2013) Genetic analysis of adult plant resistance to yellow rust and leaf rust in common spring wheat Quaiu 3. Plant Disease 97:728-736, https://doi. org/10.1094/PDIS-02-12-0141-RE

Beddow J. M., P. G. Pardey, Y. Chai, T. M. Hurley, D. J. Kriticos, H. J. Braun, R. F. Park, W. S. Cuddy and T. Yonow (2015) Research investment implications of shifts in the global geography of wheat stripe rust. Nature Plants 1:15132, http://doi.org/10.1038/ nplants.2015.132

Bulli P., J. Zhang, S. Chao, X. Chen and M. Pumphrey (2016) Genetic architecture of resistance to stripe rust in a global winter wheat germplasm collection. G3: Genes, Genomes, Genetics 6:22372253, http://dx.doi.org/10.1534/g3.116.028407

Chen W., C. Wellings, X. Chen, Z. Kang and T. Liu (2014) Wheat stripe (yellow) rust caused by Puccinia striiformis f. sp. tritici. Molecular Plant Pathology 15:433-446, https://doi.org/10.1111/mpp.12116

Dyck P. L. (1987) The association of a gene for leaf rust resistance with the chromosome 7D suppressor of stem rust resistance in common wheat. Genome 29:467-469, https://doi.org/10.1139/ g87-081

Dyck P. L., D. J. Samborski and J. W. Martens (1985) Inheritance of resistance to leaf rust and stem rust in the wheat cultivar Glenlea. Canadian Journal of Plant Pathology 7:351-354.

Evans L. E., L. H Shebeski, R. C. McGinnis, K. G. Briggs and D. Zuzens (1972) Glenlea red spring wheat. Canadian Journal of Plant Science 52:1081-1082, https://doi.org/10.4141/cjps72-184

FAOSTAT, Food and Agriculture Organization of the United Nations (2018) Crops. Food and Agriculture Organization of the United Nations. Rome, Italy. http://www.fao.org/faostat/en/\#data/QC (Diciembre 2018).

Fetch T., B. McCallum, J. Menzies, K. Rashid and A. Tenuta (2011) Rust diseases in Canada. Prairie Soils and Crops Journal 4:86-96.

García-León E., J. Huerta-Espino, H. E. Villaseñor-Mir, J. S. Sandoval-Islas, S G. Leyva-Mir, I. Benítez-Riquelme y S. Cruz-Izquierdo (2018) Genética de la resistencia a la roya del tallo en planta adulta en genotipos élite de trigo harinero. Revista Fitotecnia Mexicana 41:385-392.

Herrera-Foessel S. A., R. P. Singh, M. Lillemo, J. Huerta-Espino, S. Bhavani, S. Singh, C. Lan, V. Calvo-Salazar and E. S. Lagudah (2014) Lr67/ Yr46 confers adult plant resistance to stem rust and powdery mildew in wheat. Theoretical and Applied Genetics 127:781789, https://doi.org/10.1007/s00122-013-2256-9

Hovmøller M. S., C. K. Sørensen, S. Walter and A. F. Justesen (2011) Diversity of Puccinia striiformis on cereals and grasses. Annual Review of Phytopathology 49:197-217, https://doi.org/10.1146/ annurev-phyto-072910-095230

Huerta E. J., R. Torres G., M. F. Rodríguez G., H. E. Villaseñor M., S. G. Leyva M. y E. Solís M. (2012) Resistencia a roya amarilla (Puccinia striiformis f. sp. tritici) en variedades de trigo harinero (Triticum aestivum L.). Revista Mexicana de Ciencias Agrícolas 3:879891

Kolmer J. A. and J. Q. Liu (2002) Inheritance of leaf rust resistance in the wheat cultivars AC Majestic, AC Splendor, and AC Karma. Canadian Journal of Plant Pathology 24:327-331, https://doi. org/10.1080/07060660209507017

Lagudah E. S. (2011) Molecular genetics of race non-specific rust resistance in wheat. Euphytica 179:81-91, http://doi. org/10.1007/s10681-010-0336-3

Lagudah E. S., H. McFadden, R. P. Singh, J. Huerta-Espino, H. S. Bariana and W. Spielmeyer (2006) Molecular genetic characterization of the Lr34/Yr18 slow rusting resistance gene region in wheat Theoretical and Applied Genetics 114:21-30, https://doi org/10.1007/s00122-006-0406-z

Lalama H. M. (1974) 'Romero 73' y 'Cayambe 73': dos nuevas variedades de trigo para la siembra ecuatoriana. Boletín Divulgativo No. 69 Instituto Nacional de Investigaciones Agropecuaria, Estación Experimental "Santa Catalina". Quito, Ecuador. 11 p.

Maccaferri M., J. Zhang, P. Bulli, Z. Abate, S. Chao, D. Cantu, E. Bossolini, X. Chen, M. Pumphrey and J. Dubcovsky (2015) A genome-wide association study of resistance to stripe rust (Puccinia striiformis f. sp. tritici) in a worldwide collection of hexaploid spring wheat (Triticum aestivum L.). G3: Genes, Genomes, Genetics 5:449-465, https://doi.org/10.1534/g3.114.014563

McCallum B. D., C. W. Hiebert, S. Cloutier, G. Bakkeren, S. B. Rosa, D. G Humphreys, G. F. Marais, C. A. McCartney, V. Panwar, C. Rampitsch, B. J. Saville and X. Wang (2016) A review of wheat leaf rust research and the development of resistant cultivars in Canada. Canadian Journal of Plant Pathology 38:1-18, https://doi.org/10.1080/07 060661.2016 .1145598

McCallum B. D., X. Chen, S. Shorter, R. S. Sadasivaiah and J. P. Tewari (2007) Stripe rust reaction of 28 Canadian wheat cultivars. Canadian Journal of Plant Pathology 29:401-407, https://doi org/10.1080/07060660709507486

McIntosh R. A., J. Dubcovsky, W. J. Rogers, C. F. Morris, R. Appels and X. C. Xia (2012) Catalogue of gene symbols for wheat: 2012 supplement Annual Wheat Newsletter 58:259-279.

McIntosh R. A., J. Dubcovsky, W. J. Rogers, C. F. Morris, R. Appels and X. C. Xia (2014) Catalogue of gene symbols for wheat: 2013-2014 supplement. Annual Wheat Newsletter 60:153-175.

Mellado Z. M. (2007) El Trigo en Chile: Cultura, Ciencia y Tecnología Centro Regional de Investigación Quilamapu, Instituto de Investigaciones Agropecuarias. Chillán, Chile. 684 p.

Niks R. E., J. E. Parlevliet, P. Lindhout and Y. Bai (2011) Breeding Crops with Resistance to Diseases and Pests. Wageningen Academic Publishers. Wageningen, The Netherlands. 200 p, https://doi 
org/10.3920/978-90-8686-171-2

Peterson R. F., A. B. Campbell and A. E. Hannah (1948) A diagrammatic scale for estimating rust intensity on leaves and stems of cereals. Canadian Journal of Research 26c:496-500, http://doi. org/10.1139/cjr48c-033

Ponce-Molina L. J., J. Huerta-Espino, R. P. Singh, B. R. Basnet, G. Alvarado, M. S. Randhawa, C. X. Lan, V. H. Aguilar-Rincón, R. Lobato-Ortiz and J. J. García-Zavala (2018) Characterization of leaf rust and stripe rust resistance in spring wheat 'Chilero'. Plant Disease 102:421-427, https://doi.org/10.1094/PDIS-11-16-1545-RE

Roelfs A. P., R. P. Singh y E. E. Saari (1992) Las Royas del Trigo. Conceptos y Métodos para el Manejo de esas Enfermedades. CIMMYT. México, D. F. 81 p.

Rosewarne G. M., S. A. Herrera-Foessel, R. P. Singh, J. Huerta-Espino, C. X. Lan and Z. H. He (2013) Quantitative trait loci of stripe rust resistance in wheat. Theoretical and Applied Genetics 126: 2427-2449, http://doi.org/10.1007/s00122-013-2159-9

Rosewarne G. M, R. P. Singh, J. Huerta-Espino, H. M. William, S. Bouchet, S. Cloutier, H. McFadden and E. S. Lagudah (2006) Leaf tip necrosis, molecular markers and $\beta 1$-proteasome subunits associated with the slow rusting resistance genes $L$ r46/Yr29. Theoretical and Applied Genetics 112:500-508, https://doi.org/10.1007/ s00122-005-0153-6

Singh R. P. (1992a) Association between gene Lr34 for leaf rust resistance and leaf tip necrosis in wheat. Crop Science 32:874-878, https:// doi.org/10.2135/cropsci1992.0011183X003200040008x

Singh R. P. (1992b) Genetic association of leaf rust resistance gene Lr34 with adult plant resistance to stripe rust in bread wheat. Phytopathology 82:835-838, https://doi.org/10.1094/ Phyto-82-835

Singh R. P., D. P. Hodson, Y. Jin, E. S. Lagudah, M. A. Ayliffe, S. Bhavani, M. N. Rouse, Z. A. Pretorius, L. J. Szabo, J. Huerta-Espino, B. R. Basnet, C. Lan and M. S. Hovmøller (2015) Emergence and spread of new races of wheat stem rust fungus: continued threat to food security and prospects of genetic control. Phytopathology 105:872-884, https://doi.org/10.1094/PHYTO-01-15-0030-FI

Singh R. P., J. Huerta-Espino, S. Bhavani, S. A. Herrera-Foessel, D. Singh, P. K. Singh, G. Velu, R. Mason, Y. Jin, P. Njau and J. Crossa (2011) Race non-specific resistance to rust diseases in CIMMYT spring wheats. Euphytica 179:175-186, https://doi.org/10.1007/ s10681-010-0322-9

Singh R. P., J. Huerta-Espino and H. M. William (2005) Genetics and breeding for durable resistance to leaf and stripe rusts in wheat. Turkish Journal of Agriculture and Forestry 29:121-127.

Singh R. P., J. Huerta-Espino and S. Rajaram (2000) Achieving nearimmunity to leaf and stripe rusts in wheat by combining slow rusting resistance genes. Acta Phytopathologica et
Entomologica Hungarica 35:133-139.

Singh R. P., A. Mujeeb-Kazi and J. Huerta-Espino (1998) Lr46: a gene conferring slow-rusting resistance to leaf rust in wheat Phytopathology 88:890-894, https://doi.org/10.1094/ PHYTO.1998.88.9.890

Singh R. P. and S. Rajaram (1992) Genetics of adult-plant resistance of leaf rust in 'Frontana' and three CIMMYT wheats. Genome 35:24-31, http://doi.org/10.1139/g92-004

Singh R. P. and S. Rajaram (1993) Genetic of adult plant resistance to stripe rust in ten spring bread wheats. Euphytica 72:1-7. http:// doi.org/10.1007/BF00023766

Solh M., K. Nazari, W. Tadesse and C. R. Wellings (2012) The growing threat of stripe rust worldwide. In: Proceedings of the GBR1 2012 Technical Workshop, 1-4 September 2012. Borlaug Global Rust Initiative. Beijing, China. pp:1-10

Solís M. E., J. Huerta E., P. Pérez H., H. E. Villaseñor M., A. Ramírez R. y M. L. de la Cruz G. (2016) Alondra F2014, nueva variedad de trigo harinero para el Bajío, México. Revista Mexicana de Ciencias Agrícolas 7:1225-1229.

Suaste F. M. P., V. M. Zamora V., M. H. Reyes V., H. E. Villaseñor M., A. Santacruz V. y E. Solís M. (2015) Agrupamiento de genotipos de la colección nacional de trigo en base a genes de interés agronómico. Revista Mexicana de Ciencias Agrícolas 6:695-706.

Uauy C., J. C. Brevis, X. Chen, I. Khan, L. Jackson, O. Chicaiza, A. Distelfeld T. Fahima and J. Dubcovsky (2005) High-temperature adult-plant (HTAP) stripe rust resistance gene Yr36 from Triticum turgidum ssp. dicoccoides is closely linked to the grain protein content locus Gpc-B1. Theoretical and Applied Genetics 112:97-105 https://doi.org/10.1007/s00122-005-0109-x

Villaseñor-Espín Ó. M., J. Huerta-Espino, S. G. Leyva-Mir, H. E. Villaseñor-Mir, R. P. Singh, J. S. Sandoval-Islas y E. Espitia-Rangel (2009) Genética de la resistencia a roya amarilla en plantas adultas de trigo harinero. Revista Fitotecnia Mexicana 32:217-223.

Wellings C. R. (2011) Global status of stripe rust: a review of historical and current threats. Euphytica 179:129-141, https://doi. org/10.1007/s10681-011-0360-y

William M., R. P. Singh, J. Huerta-Espino, S. Ortiz Islas and D. Hoisington (2003) Molecular marker mapping of leaf rust resistance gene Lr46 and its association with stripe rust resistance gene Yr29 in wheat. Phytopathology 93:153-159, https://doi.org/10.1094/ PHYTO.2003.93.2.153

Zhang R., R. P. Singh, M. Lillemo, X. He, M. S. Randhawa, J. Huerta-Espino, P. K. Singh, Z. Li and C. Lan (2019) Two main stripe rust resistance genes identified in synthetic-derived wheat line Soru\#1. Phytopathology 109:120-126, https://doi.org/10.1094/PHYTO04-18-0141-R 